\title{
Influence of the Precipitated Graphite on the Determinations of Gases Contents in Iron by Vacuum Fusion Method Using Graphite Crucible*
}

\section{By Yoshihiko ABE**}

\begin{abstract}
Synopsis
Vacuum-degassing of iron melt in graphite crucible has been investigated by accomplishing the complete determination of gases in iron with vacuum fusion method. When the carbon saturated iron melt is healed in a crucible precipitated graphite is formed at first and then grows to a flake form as the time and the temperature of melting increase. This graphite precipitated in the melt absorbs strongly hydrogen and decreases the diffusion velocities of gases in the melt, especially nitrogen. These disadvantages can be reduced by the simultaneous addition of spheroidal graphite-forming materials such as cerium, by the use of closed type crucible and by the generation of gas bubble in the melt, respectively. Formation mechanism of flaky graphite was also discussed, based on the experimental results obtained.
\end{abstract}

\section{Introduction}

Vacuum melting technique is mostly desirable way for the removal of gases contained in iron and steel such as hydrogen, oxygen, and nitrogen. Among these gases oxygen and nitrogen exist mainly in the combined forms of oxides and nitrides, and the equilibrium pressures of these gases, which are given solely by the equilibrium constants of the reactions, are greatly increased by carbon in the melt. The use of carbon-saturated melt, which is easily produced by heating iron in a graphite crucible, may therefore be indispensable for rapid and complete degassing.

From the above-mentioned standpoints, it seems to be better to use the vacuum fusion method with the aid of graphite crucible for quantitative determination of the gases in iron and steel. However, when iron is vacuum-fusioned in a graphite crucible the precipitation of graphite cannot be prevented. In addition, it is well known that the degassing rate of liquid iron having suspended particles such as the precipitated graphite is greatly afffected by the amount and by the shape of particles. ${ }^{1-6)}$ Applying the above theoretical advantage on the use of graphite crucible, the present investigation has been undertaken to provide such vacuum melting conditions for iron melts as the effect of precipitated graphite is diminished as much as possible.

\section{Experimental Procedure}

A schematic diagram of the furnace used for the experiments is shown in Fig. 1. The furnace was heated by the resistance consisted of two concentric graphite tubes, into which the graphite crucible was inserted, up to the temperature range of $700^{\circ}$ and $2000^{\circ} \mathrm{C}$. The small and large graphite funnels were fixed on the top of the furnace for introducing the sample.

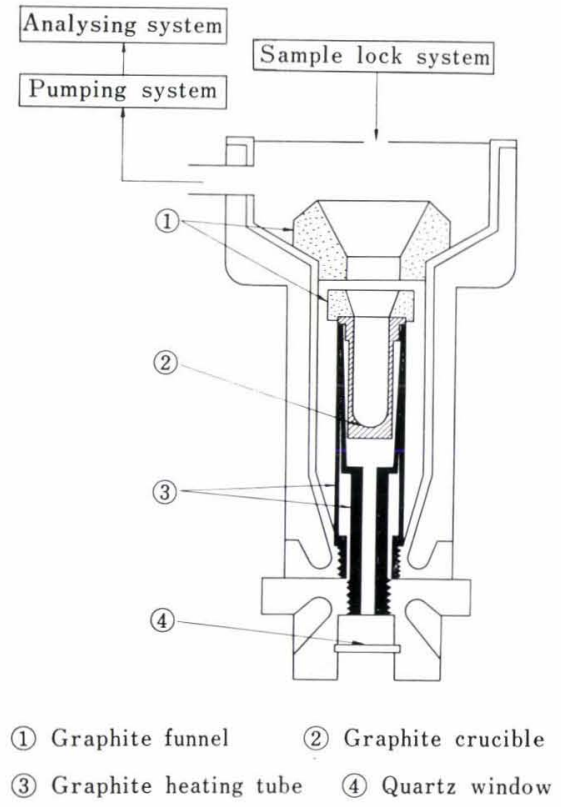

Fig. 1. Schematic diagram of vacuum fusion furnace

Temperature of the melts was adjusted by means of a temperature rating diagram in which the relation between the heater current indicated on the ammeter and the thermal radiation of the crucible bottom obtained through the deviating mirror was plotted in a double logarithmic coordinate scale. Temperature calibration was previously made by measuring the melting points of pure platinum and gold.

Vacuum system of the furnace consists of an oil diffusion pump having pumping speed of about $170 \mathrm{l} / \mathrm{sec}$ and a rotary vane pump. The ultimate pressure of the furnace was about $10^{-6} \mathrm{mmHg}$ in case that this vacuum system was used.

When the sample was treated in the above vacuum fusion furnace, the gases containing in the sample were transferred to an analysing system, in which the total quantity of the gases and the partial quantities of respective gas components were determined by the respective measurements of total pressure, thermal conductivity and infra-red absorption. The standard deviations of these measurements were $\pm 0.33 \%$ for $0.5 \mathrm{cc} \mathrm{CO}, \pm 0.56 \%$ for $0.5 \mathrm{cc} \mathrm{H}_{2}$, and $\pm 0.6 \%$ for 1.0 cc $\mathrm{N}_{2}$, respectively.

Table 1 shows the chemical composition of the sample used. The sample used for an experiment was about $2 \mathrm{~g}$ in weight and $8 \mathrm{~mm} \phi$ in diameter. The

* This paper is originally based on the data published in Tetsu-to-Hagané, 54 (1968), 520 ; 55 (1969), 839 ; and 56 (1970), 351 , in Japanese. English version received March 17, 1970.

** Technical Research Laboratory, Mitsubishi Steel Mfg. Co., Ltd., Koto-ku, Tokyo 135. 
Table 1. Chemical composition of the sample used (\%)

\begin{tabular}{ccccccccccccc}
\hline $\mathrm{G}$ & $\mathrm{Si}$ & $\mathrm{Mn}$ & $\mathrm{P}$ & $\mathrm{S}$ & $\mathrm{Ni}$ & $\mathrm{Cr}$ & $\mathrm{Al}$ & $\mathrm{H}$ & $\mathrm{O}$ & $\mathrm{N}$ \\
\hline 0.89 & 0.26 & 0.49 & 0.013 & 0.014 & 0.05 & 0.16 & 0.018 & $\begin{array}{c}0.00023 \text { to } \\
0.00027\end{array}$ & $\begin{array}{c}0.0033 \text { to } \\
0.0036\end{array}$ & $\begin{array}{c}0.0034 \\
0.0037\end{array}$ \\
\hline
\end{tabular}

Table 2. Chemical composition of Ni-Ce alloy used (\%)

\begin{tabular}{cccccc}
\hline $\mathrm{C}$ & $\mathrm{Ni}$ & $\mathrm{Ce}$ & $\mathrm{H}$ & $\mathrm{O}$ & $\mathrm{N}$ \\
\hline 4.0 & 83.40 & 6.7 & 0.00031 & 0.0032 & 0.0012 \\
\hline
\end{tabular}

metals provided for the experiments except cerium which was used for the preparation of $\mathrm{Ni}-\mathrm{Ce}$ alloy were previously purified by the degassing treatment. The chemical composition of $\mathrm{Ni}-\mathrm{Ce}$ alloy used is shown in Table 2.

\section{Experimental Results}

1. Removal of Gas from Iron Melt and the Behavior of Graphite Precipitated in Iron Melt

The sample with previous melting at $1800^{\circ} \mathrm{C}$ for $4 \mathrm{~min}$ and the sample without previous melting were both melted in graphite crucibles in order to investigate the effect of carbon on the degassing behavior of molten iron. Variations of degassing rates of hydrogen, oxygen, and nitrogen for the time of melting were shown in Fig. 2. On this experiments the liquid iron which was previously melted would already be saturated by carbon before the addition of sample, and the liquid which was not previously melted would be gradually saturated by carbon after the addition of sample. The difference between the degassing rates shown in Fig. 2 should therefore be corresponded to the difference between the rates of carbon saturation. As it is obvious from Fig. 2, the trend of the variation of degassing rate of oxygen is quite similar to that of nitrogen, but not for hydrogen.

Another experiments were also made to investigate the variation of the distribution of graphite in the melt during $4 \mathrm{~min}$ of previous melting. Distributions of graphite in lqiuid iron melted previously at $1800^{\circ} \mathrm{C}$ are micrographically shown in Photo. 1. As seen from these photographs shown in Photo. 1, the amount of graphite produced in the melt for $15 \mathrm{sec}$ after melting, for which a great part of the gas transpired from the melt, is a slightly small, but the precipitated graphite increases greatly for the time more than $60 \mathrm{sec}$ and the precipitated graphite grows in flake form as the time of melting increases. The effect of precipitated graphite on the degassing of the melt should therefore be related to both its amount and its shape.

\section{Absorption of Gas by Graphite}

To explain the cause for the decrease of degassing rate by precipitated graphite, absorption of gases by graphite has also been investigated by the following procedure: $0.3 \mathrm{cc}$ of pure gas was introduced to the furnace in which the gas-free graphite crucible was set and maintained for one minute, then degassed. Figure 3 shows the result obtained over the tem-

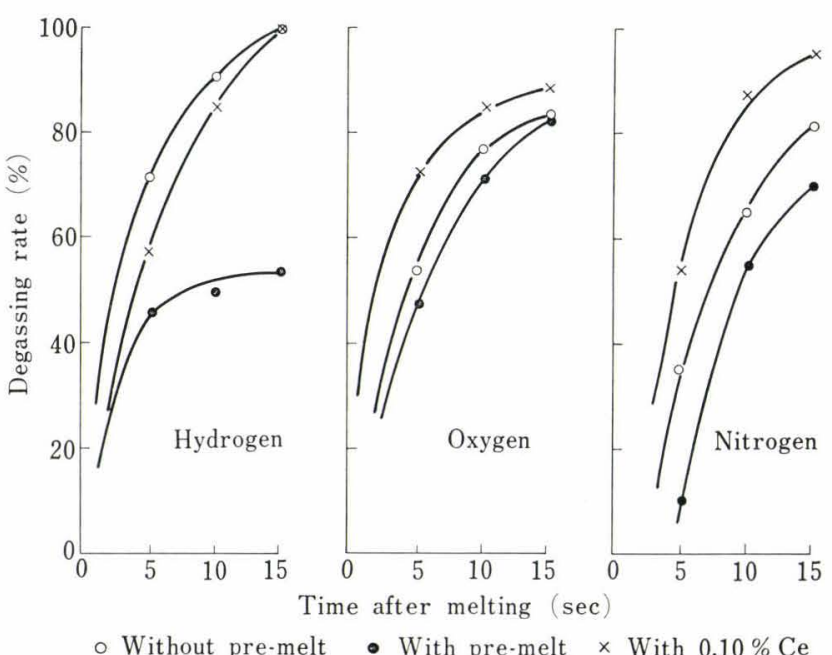

Fig. 2. Change of degassing rate of liquid iron with melting time under various conditions (samples were melted in graphite crucibles at $1800^{\circ} \mathrm{C}$ )

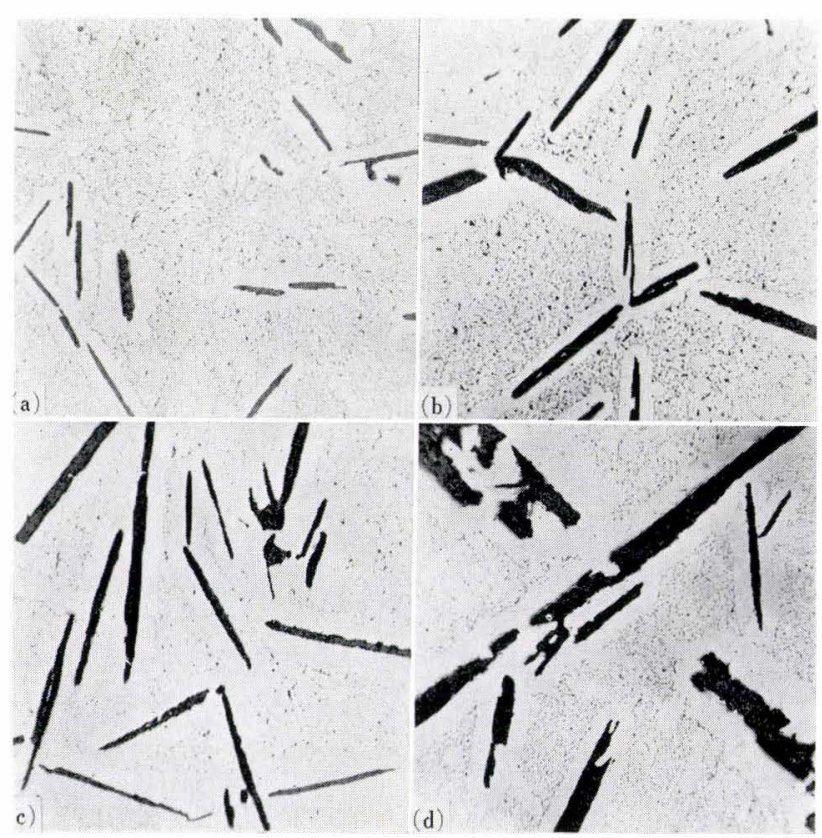

Photo. 1. Distribution of graphite formed in iron melts heated in a graphite crucible at $1800^{\circ} \mathrm{G}$ $\left(\times 100 \times \frac{2}{3}\right)$
(a) $15 \mathrm{sec}$ after melting
(b) $30 \mathrm{sec}$ after melting
(c) $60 \mathrm{sec}$ after melting
(d) 4 min after melting

perature range $1100^{\circ}$ to $1800^{\circ} \mathrm{C}$. It can be seen from this figure that graphite does not absorb carbon monoxide and nitrogen in spite of high temperature, but not hydrogen. In addition, the ability of hydrogen absorption of graphite remarkably increases with increasing temperature and holding time as shown in Fig. 4, in which the amounts of hydrogen absorbed by graphite at $1100^{\circ}, 1500^{\circ}$, and $1800^{\circ} \mathrm{C}$ are also illus- 


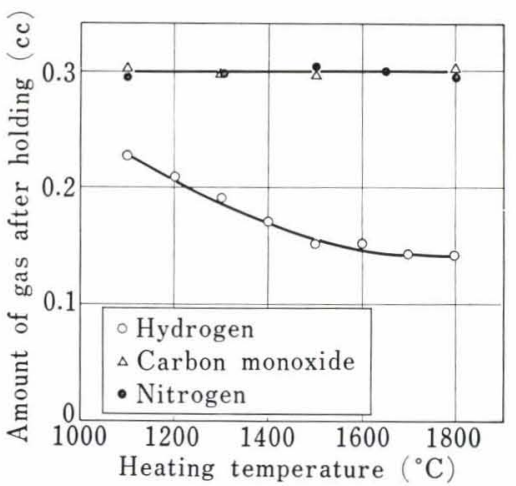

Fig. 3. Gas absorption of graphite over the temperature range $1100^{\circ}$ to $1800^{\circ} \mathrm{C}$

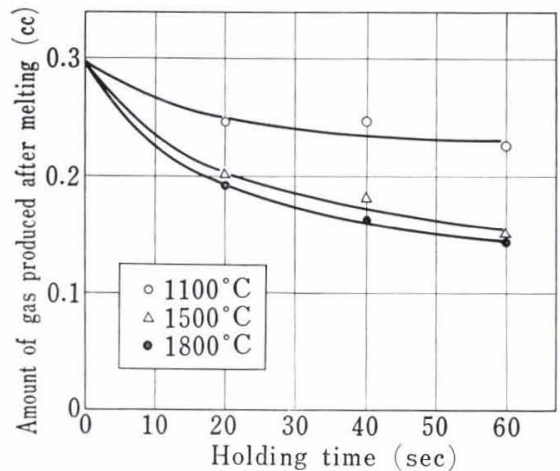

Fig. 4. Hydrogen absorption of graphite at $1100^{\circ}, 1500^{\circ}$ and $1800^{\circ} \mathrm{C}$

trated for the comparison.

From the results obtained by the above-mentioned experiments, it may be considered that low degassing rate of hydrogen shown in Fig. 2 depends on hydrogen absorption of graphite, mainly the graphite precipitated in the melt because it is produced in the melt during the previous melting.

In order to confirm this, the sample was continuously melted in a graphite crucible at various temperature and the amount of transpired hydrogen was analysed. The summarized results are shown in Fig. 5. As shown in this figure, 1st samples without previous melting show complete degassing regardless of the heating temperature, but the degassing of the other samples becomes incomplete in close connection with the increase of the time of previous melting, on which the amount and the growth rate of flaky graphite increase.

On the other hand, the investigation for the degassing of sample in graphite crucible was also made to distinguish the effect of graphite when the sample is in solid state. As shown in Fig. 6, the degassing rate of hydrogen increases with increasing number of added samples and increasing temperature. Since all of the samples added do not contain the precipitated graphite, the loss of degassing should be resulted from the hydrogen absorption of graphite crucible. Of course the loss of degassing increases with increasing temperature as shown in Fig. 4. On the other hand, the degassing rate of hydrogen increases as the tem-

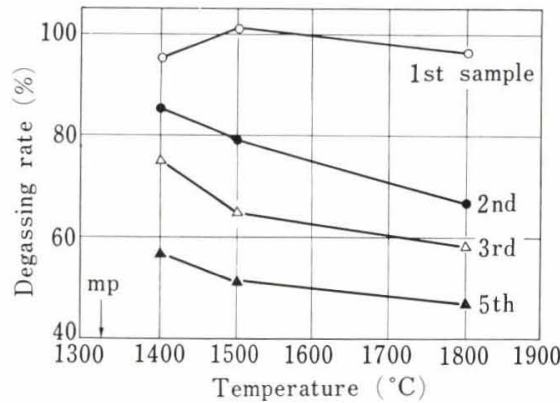

Fig. 5. Degassing of hydrogen from the melt formed in a graphite crucible under various conditions

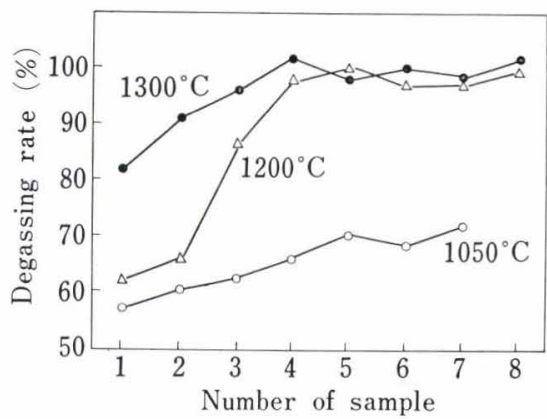

Fig. 6. Degassing rate of hydrogen when sample is continuously vacuum-heated in a graphite crucible

perature increases. It is therefore considered that the hydrogen absorption by graphite crucible may proceed slowly and becomes to be neglected when the sample is in liquid state where the degassing proceeds rapidly, and that the loss of hydrogen degassing on liquid iron is thus related only the hydrogen absorption of precipitated graphite. The loss of hydrogen degassing may be estimated from the amount and the growth rate of precipitated graphite in flake form.

\section{Shape of the Graphite Precipitated in the Melt and Its Effect on the Gas Transpiration from the Melt}

Previous investigators reported that the precipitated graphite increases the viscosity of the melt, ${ }^{1)-3)}$ due to the increase of axial ratio of its particles, ${ }^{5)}$ which is an important parameter of the degassing rate. ${ }^{7)}$ It is also known that the degassings of carbon monoxide and nitrogen having comparatively slow velocity than that of hydrogen may be affected by the amount and the shape of precipitated graphite. To confirm these facts, additional experiments were made by adding a small amount of cerium to the melt simultaneously and the results obtained from this experiment for the degassing rate were also illustrated in Fig. 2 for comparison. The effect of cerium on carbon-saturated melts may be caused by the action of spheroidal graphite-forming elements. ${ }^{8)-10)}$ The increase of degassing rate due to the simultaneous addition of cerium shown in Fig. 2 may therefore indicate that the degassing is accelerated so far as the graphite is precipitated in spheroidal form.

Additional experiment was carried out to find the practical effect of cerium for rapid and complete de- 
gassing of the iron melt formed in a graphite crucible ; the samples containing $0.1 \%$ cerium were continuously added into a vacuum fusion furnace and the gas transpired from the sample was analysed by the measuring device attached to the system. The results obtained are shown in Fig. 7 in comparison with the data obtained for the sample not containing cerium. As shown in Fig. 7, the effect of cerium is remarkable on the degassing of first sample melted in empty graphite crucible. However, it becomes gradually less for the following samples, although there is a considerable difference among the kinds of gases transpired. This experimental evidence indicates that the effect of cerium served as the spheroidal graphite-forming element does not continue at high temperature and that the amount of effective cerium decreases with increasing volume of the melt. To minimize the above disadvantages, a greater amount of cerium was added to the melt under the same experimental condition, but the values determined for oxygen and nitrogen were less than those previously obtained.

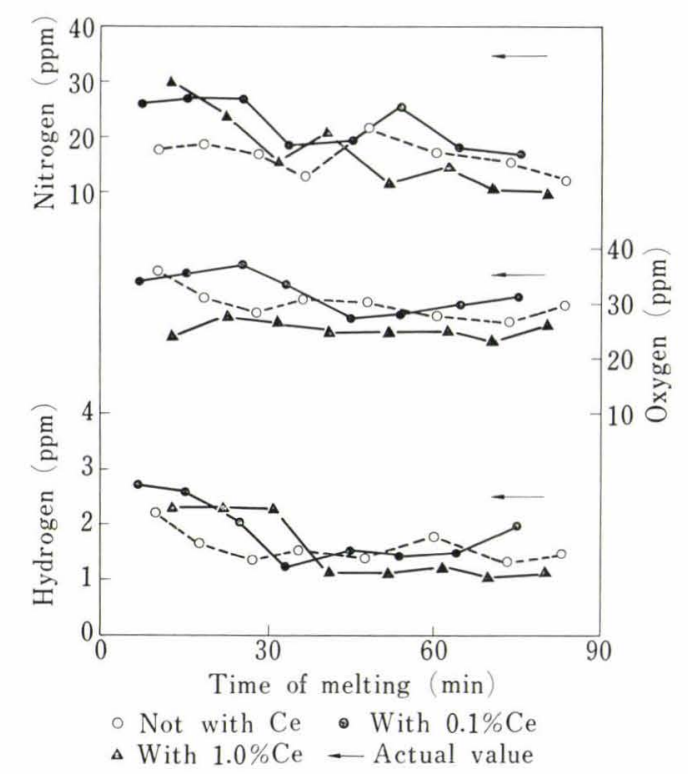

Fig. 7. Analytical results of the gases transpired from the sample continuously added to a graphite crucible placed in the vacuum fusion furnace

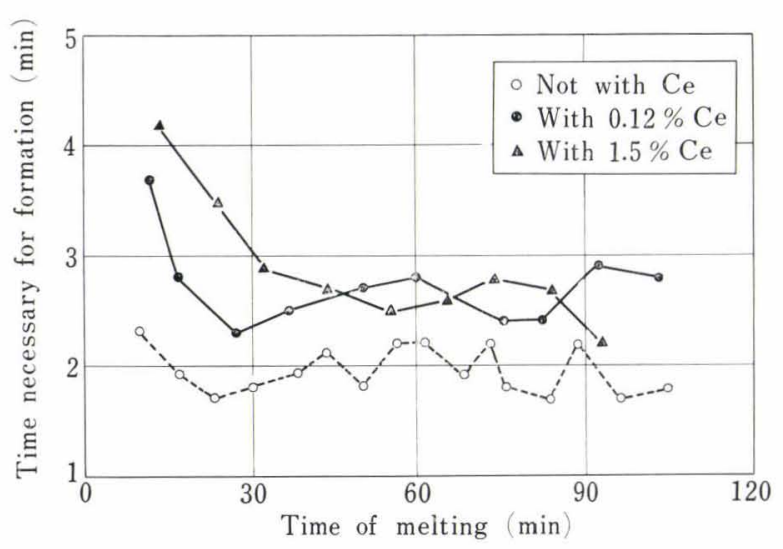

Fig. 8. Effect of cerium on the formation of graphite film on the surface of melt
In addition, the time necessary for the formation of surface film, which is corresponding to the amount and the growth rate of precipitated graphite in flake form, is also experimentally checked. The results obtained are shown in Fig. 8 by comparing with the data of no cerium content. As shown in this figure, the co-existence of a small amount of cerium is usually effective to prevent the above phenomena, but the addition of a greater amount of cerium is not always so effective except for the primary period of melting. The results of these observations may be summarized as follows: the sufficient amount of precipitated graphite in spheroidal form is formed by the addition of a small amount of cerium, and the addition of a greater amount of cerium may be obliged to decrease the degassing rate of melt, because of its strong affinities for oxygen and nitrogen.

\section{Use of a Closed Type Crucible}

The longitudinal sections of the melts solidified in an opened crucible after heating for 1 and $4 \mathrm{~min}$ are shown in Photo. 2 , in which the precipitated graphite in flake form begins to grow from the surface layer of the melt. These photographs obviously indicate that the formation of flaky graphite is mainly depending on the temperature gradient of the melt and that this peculiar tendency may be decreased by the use of closed type crucible because it alleviates the temperature gradient of the melt.

To compare with the one shown in Photo. 1, an additional test was made by using a closed type crucible under the same experimental conditions. As can be seen in Photo. 3, the amount of graphite precipitated in the crucible is the same as the former, but the growth rate of flake form graphite is greatly less than that of the former. Effect due to the difference among micrographic structures of precipitated graphite is as shown in Table 3 which is listed the removal rate of the gases in iron melt. Of course the degassings of hydrogen and nitrogen from the iron melt are not complete regardless of the melt without previous melting, but the amount of nitrogen degassed in a closed type crucible is more than that in an opened crucible. On the contrary, hydrogen is hardly degassed in a closed type crucible because the amount of hydrogen absorption by graphite increases due to the increase of surface area of crucible.

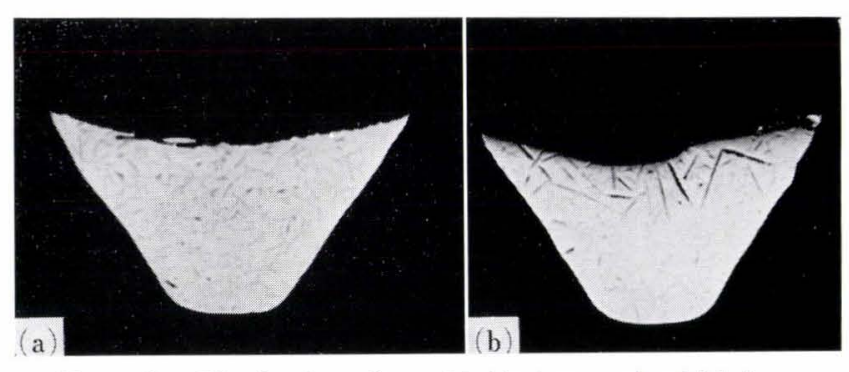

Photo. 2. Distribution of graphite in iron melt which is solidified in a graphite crucible $\left(\times 3 \times \frac{3}{4}\right)$

(a) Holding time $1 \mathrm{~min}$ at $1800^{\circ} \mathrm{C}$

(b) Holding time $4 \mathrm{~min}$ at $1800^{\circ} \mathrm{C}$ 


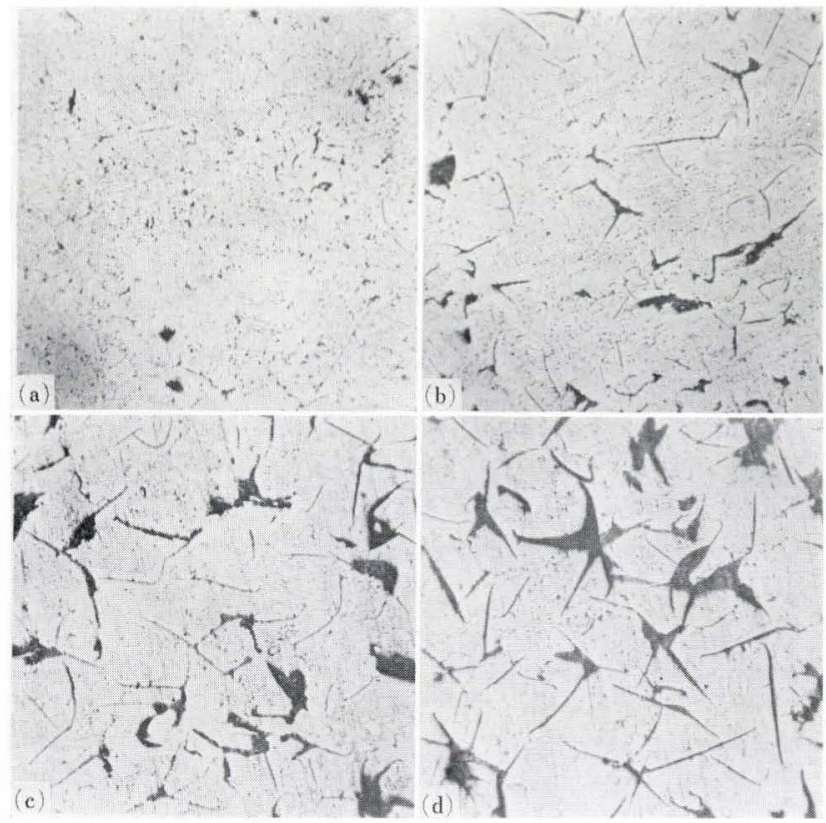

Photo. 3. Distribution of graphite formed in iron melt heated in a closed type graphite crucible at $1800^{\circ} \mathrm{C}$ $\left(\times 100 \times \frac{2}{3}\right)$
(a) $15 \mathrm{sec}$ after melting
(b) $30 \mathrm{sec}$ after melting
(c) $60 \mathrm{sec}$ after melting
(d) 4 min after melting

Table 3. Gases transpired from iron melt under various conditions

\begin{tabular}{|c|c|c|c|c|c|c|c|}
\hline \multirow{3}{*}{ Crucible } & \multirow{3}{*}{$\begin{array}{l}\text { Volatile } \\
\text { element } \\
\text { added }\end{array}$} & \multicolumn{6}{|c|}{ Degassing yield $(\%)$} \\
\hline & & \multicolumn{3}{|c|}{ Without Ce addition } & \multicolumn{3}{|c|}{ With Ce addition } \\
\hline & & $\mathrm{H}$ & $\mathrm{O}$ & $\mathrm{N}$ & $\mathrm{H}$ & $\mathrm{O}$ & $\mathrm{N}$ \\
\hline Closed & - & $\begin{array}{c}30 \text { to } \\
60\end{array}$ & 100 & $\begin{array}{c}65 \text { to } \\
85\end{array}$ & - & - & - \\
\hline \multirow{4}{*}{ Opened } & - & $\begin{array}{c}60 \text { to } \\
72\end{array}$ & 100 & $\begin{array}{c}39 \text { to } \\
56\end{array}$ & 92 & 100 & $\begin{array}{c}72 \text { to } \\
80\end{array}$ \\
\hline & $\mathrm{Zn}(6 \%)$ & 88 & 94 & $\begin{array}{c}47 \text { to } \\
59\end{array}$ & - & - & - \\
\hline & $\mathrm{Sb}(6 \%)$ & $\begin{array}{c}20 \text { to } \\
40\end{array}$ & 94 & $\begin{array}{c}53 \text { to } \\
72\end{array}$ & 96 & 97 & $\begin{array}{c}78 \text { to } \\
95\end{array}$ \\
\hline & $\operatorname{Ag}(6 \%)$ & - & 91 & $\begin{array}{c}53 \text { to } \\
70\end{array}$ & - & 100 & $\begin{array}{c}72 \text { to } \\
92\end{array}$ \\
\hline
\end{tabular}

\section{Co-existence of Volatile Element}

The temperature gradient of the melt which is effective for the formation of flaky graphite may be reduced by stirring of the melt. In order to reduce the temperature gradient of the melt, the gas bubble method may be considered as the suitable one. The experiment was therefore made by the addition of silver, which is a strong volatile metal. It is obvious from Photo. 4 that silver vapor forms gas bubbles in the melt and prevents the growth of flake-like graphite particle.

Quantitative effect of gas bubble is shown in Table 3 by comparing the amounts of transpired gas from the melts with and without cerium. Time of stirring was adjusted by choosing the volatile metals having low affinities of oxygen and nitrogen. The gas bubble method has an appreciable effect on the transpiration

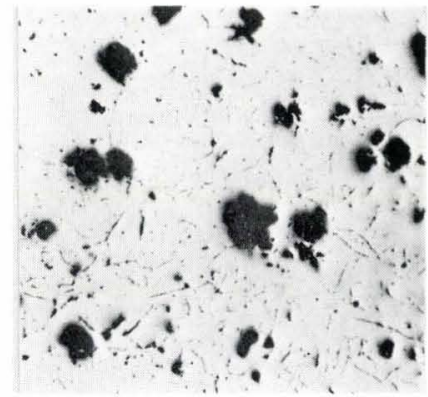

Photo. 4. Distribution of graphite formed in iron melt heated for $30 \mathrm{sec}$ by the addition of $5 \%$ silver $\left(\times 100 \times \frac{2}{3}\right)$

of hydrogen and nitrogen in the sense that zinc is available for hydrogen transpiration and antimony and silver for the removal of nitrogen. However, the time of stirring due to the addition of zinc is shorter than that of antimony and silver, because of the difference in their vapor pressures. From this reason, it will be desirable that the addition of zinc is to increase the transpiration of hydrogen having high degassing velocity and that antimony or silver is added for acceralating the transpiration of the gas of comparatively slow degassing rate such as nitrogen.

\section{Discussion}

When iron is vacuum-fusioned in a graphite crucible, the gases contained in it may be transpired through the following steps:

(1) Transport of graphite from the crucible to the melt,

(2) Decomposition of gaseous compounds (oxides, nitrides) by graphite,

(3) Transport of gases in the melt,

(4) Transport of gases from the liquid phase to the gas phase,

(5) Transport of gases in the gas phase.

Quantity of the gas emerging from the melt in unit time may be given as follows:

$$
\frac{-d G}{d t}=\beta \cdot \frac{F}{V}\left(C_{\infty}-C_{o}\right)
$$

$$
\begin{aligned}
& \text { where, } \quad \begin{aligned}
\beta: & \text { mass transfer coefficient } \\
F: & \text { effective surface area } \\
V: & \text { volume of the melt } \\
C_{\infty}: & \text { initial concentration of gas in the melt } \\
C_{o}: & \text { solubility of gas in the melt. }
\end{aligned}
\end{aligned}
$$

On this degassing process the gaseous compounds such as oxides and nitrides may be decomposed by the graphite which is supplied from the crucible at the melting if it is not previously melted and by the graphite precipitated in the melt at the melting if it is previously melted. Thus the first step of the process mentioned-above may not occur on the melting for the case without previous melting. The use of empty graphite crucible may therefore be advantageous to carry out the kinetic study of the degassing reaction since the effect of precipitated graphite is clearly estimated.

The effect of precipitated graphite on the degassing 
of iron melts can be reduced by the addition of cerium, by the use of a closed type crucible and by the generation of gas bubble in the melt, respectively. Among these, the use of a closed type crucible is also effective for the degassing of metals having high vapor pressure because the evaporation of metals is prevented.

Since the gas bubble carried out by the addition of volatile metal increases the effective surface area, the formation of spheroidal graphite is promoted, but this effect for degassing is less than that of cerium addition. This means that the effect of gas bubble which promotes the formation of spheroidal graphite is very small and that the rate of degassing through the abovementioned continuous process may be controlled by the diffusion velocity of gases in the melt, which contributes to the term of $\beta$. Effective action of gas bubble may thus be obtained by the addition of volatile metals which cause the rapid diffusion of gases in the melt, and it is generally expressed by the term of $v / F$.

In addition, the gas bubble may also be generated when the melt contains a great amount of hydrogen, oxygen, or nitrogen. In this case, the degassing takes place as the annex of the mechanism of bubble formation of their gases and the value of $\beta$ is considerably higher as compared with the degassing process given by the material exchange through the free surface of the melt. ${ }^{7}$ ) The gases contained in the melt may contribute to the increase of degassing rate if the amount of these gases is large. Of course it is necessary to present the bubble nuclei, which forms the inhomogeneities of the melt. This condition should easily be given when the crucible wall shows the surface irregularities. ${ }^{11)}$ The use of empty crucible may thus be desirable.

On the other hand, complete degassing of nitrogen was accomplished by the use of crucible lining the oxide such as magnesia or by the co-existence of diffusible oxide in the melt according to the previously published reports. ${ }^{12)-15)}$ These phenomena can be explained as follows : carbon monoxide, which is the product resulted from the decomposition of oxides in the carbon saturated melt, may diffuse in the same way as in the case of nitrogen and then gives a scavenging effect on the degassing of nitrogen. It may therefore be possible to promote the transpiration of gas from a carbon-saturated melt by scavenging if there is a great amount of other gases.

\section{Conclusion}

The difficulties found on the degassing of carbonsaturated iron melt are mainly resulted from the gas absorption of precipitated graphite and the formation of viscous melt which are responsible for the transpirations of hydrogen and nitrogen, respectively. These are found from the experimental evidences that the greater the amount and the growth rate of flakelike graphite was the greater the incompleteness of degassing was.

From the results of additional experiments made on the formation of graphite in spheroidal form, it becomes obvious that the addition of a small amount of cerium, the use of a closed type crucible, and the generation of gas bubble are all effective for the degassing from iron melts.

\section{REFERENCES}

1) W. H. Smith: Analyt. Chem., 27 (1955), 1636.

2) R. S. McDonald, J. E. Fagel, and E. W. Balis: Analyt. Chem., 27 (1955), 1632.

3) W. G. Guldner: Talanta, 8 (1961), 191

4) Th. Kraus, M. G. Frohberg, and A. Gerhardt: Arch. Eisenhüttenw., 35 (1964), 39.

5) F. Eirich and J. Risemann: J. Polymer. Sci., 4 (1949), 417.

6) A. L. Beach and W. G. Guldner: Analyt. Chem., 31 (1959), 1722 .

7) Th. Kraus: Schweiz, Arch. Angew. Wiss. Techn., 28 (1962), 452.

8) H. Morrogh and W.J. Williams: J. Iron Steel Inst., 155 (1947), 321.

9) J. Keverian, H. F. Taylor, and J. Wulff: Amer. Foundryman, 23 (1953), No. 6, 85.

10) K. Herfurth: Neue Hütte, 9 (1964), 240.

11) L. Von Bogdandy: Arch. Eisenhüttenw., 32 (1961), 287.

12) M. Tsutiya: Japan Analyst, 8 (1959), 723, 728.

13) P. Boillot, R. Boulin, and E. Jaudon: Chim. Anal., 47 (1965), 120, (Paris).

14) N. Yamaguti, T. Sudo, and D. Kanmori: Japan Analyst, 18 (1969), 13.

15) H. Goto and M. Hosoya: J. Japan Inst. Metals, 32 (1968), 1035 . 